\title{
Functional capacity in Chagas disease
}

\author{
Antonio Luiz Pinho Ribeiro ${ }^{[1]}$
}

[1]. Hospital das Clínicas, Faculdade de Medicina, Universidade Federal de Minas Gerais, Belo Horizonte, MG, Brasil.

Chagas disease remains an important health problem worldwide, with more than 6 million persons infected in Latin American endemic countries and hundreds of thousands of infected immigrants living in Europe and North America ${ }^{1}$. In Brazil, although its prevalence is declining, the Global Burden of Disease Project estimated 5,952 (range, 5,498-6,453) deaths due to Chagas disease in 2015². In 2016, among all neglected tropical diseases in Brazil, Chagas disease was the leading cause of DALYs - disability-adjusted life-years [141,640; 95\% confidence interval (95\% CI), 129,065-155,941], a measure of health loss due to fatal and non-fatal disease burden ${ }^{3}$. Chagas disease is a paradigmatic example of a neglected tropical disease, a group of preventable, stigmatizing, disabling, debilitating, and potentially lethal communicable diseases that predominantly affect the poor and vulnerable populations of the developing world ${ }^{4}$. The meaning of neglected for Chagas disease is wide and deep, and the disease has been forgotten in many different ways. Chagas disease is not always mentioned as the underlying cause of a patient's death, leading to underreporting of the number of deaths attributable to $\mathrm{it}^{5}$. Clinical trials of Chagas disease, both for specific and syndromic treatment, are scarce, and the current management of Chagas cardiomyopathy relies largely on recommendations transposed from guidelines developed for other cardiopathies ${ }^{6}$. There is also a need for comprehensive data on the clinical presentation and natural history of the disease.

In this issue, Costa et al. ${ }^{7}$ presented a study that contributes to our understanding of an important feature in Chagas disease, i.e., the existence (or not) of reduced functional capacity in different stages of the disease. Patients with dilated Chagas heart disease (CHD) undoubtedly have impaired functional capacity, but consensus is lacking about whether patients without apparent cardiopathy or with non-dilated CHD are similarly affected ${ }^{7}$. To answer this question, the authors performed a systematic review of studies that evaluated the measured or estimated peak oxygen consumption ( $\mathrm{VO}_{2}$ peak) in Chagas disease patients classified in at least one of these stages compared to that in a control group.

Corresponding author: Dr. Antonio Luiz Pinho Ribeiro.

e-mail: tom@hc.ufmg.br

Received 6 August 2018

Accepted 7 August 2018
The results were summarized and meta-analyzed to compare $\mathrm{VO}_{2}$ peak between healthy subjects and patients with Chagas disease without apparent cardiopathy, non-dilated CHD, and dilated CHD.

From 363 studies obtained using a standard strategy in several databases, only seven fulfilled the selection criteria and were included in the review. Six of these studies assessed functional capacity using a treadmill, and four of seven measured $\mathrm{VO}_{2}$ peak directly. Study quality was assessed by using the Newcastle-Ottawa scale, and random effects models were used when moderate to high heterogeneity was present. Chagas disease patients without cardiopathy $(n=208)$ had $\mathrm{VO}_{2}$ peak values similar to those of healthy controls $(n=105)$, but those with non-dilated CHD $(n=159)$ had significantly lower $\mathrm{VO}_{2}$ peak values than healthy controls (difference: 8.71, 95\% CI, $13.99-3.42 \mathrm{~mL} / \mathrm{kg} / \mathrm{min}$ ) with high heterogeneity $\left(\mathrm{I}^{2}, 75 \%\right)$. Those with dilated CHD $(n=131)$ had reduced $\mathrm{VO}_{2}$ peak values compared to healthy controls without heterogeneity in the meta-analysis.

The interpretation of these results should consider the small number of studies retrieved by the authors and the uncertainty introduced by the high heterogeneity and large $95 \%$ confidence interval observed in the meta-analytic comparison of patients with non-dilated CHD and healthy subjects, limitations acknowledged by the authors. Different studies may also have used slightly different stage definitions since there is a wide spectrum of clinical and pathological manifestations in Chagas disease patients ${ }^{1,6}$, leading to different profiles of patients included in the groups compared by the meta-analysis. However, it is important to understand why such patients without overt left ventricular systolic dysfunction seemed to have reduced capacity to exercise. One putative explanation is the presence of chronotropic incompetence observed in nondilated CHD patients, which is related to both reduced vagal heart variability indexes and reduced exercise duration and estimated $\mathrm{VO}_{2}$ peak ${ }^{8,9}$. Vagal heart dysfunction can occur even in Chagas disease patients without apparent cardiopathy ${ }^{10}$, but it worsens as the left ventricular function deteriorates with disease progression $^{11}$ and may affect exercise ability in patients with non-dilated CHD. Other mechanisms can be related to diastolic dysfunction, which can occur in early Chagas disease patients without apparent cardiopathy and is more intense in those with 
non-dilated $\mathrm{CHD}^{12}$. Functional capacity assessed by $\mathrm{VO}_{2}$ peak is related to increased left ventricular (LV) filling pressures and diastolic dysfunction independent of systolic function in patients with Chagas cardiomyopathy ${ }^{13}$. Right ventricular (RV) function, an important factor in functional capacity ${ }^{14}$, may be compromised in the early stages of Chagas disease ${ }^{15}$. Ventricular arrhythmias, a hallmark of CHD that is common in non-dilated patients ${ }^{16}$, may also be induced by exercise and impair an individual's ability to reach maximal effort. The existence of so many possible mechanisms to explain the reduced functional capacity in the early stages of CHD suggests that this phenomenon may be multifactorial and vary among patients, a feature that is compatible with the pleomorphic clinical presentation of the disease.

All of these findings stress the importance of the present study and identify the need for further studies to determine the reduction in exercise capacity in the early stages of Chagas disease and evaluate the role of exercise training in its treatment. As the authors observed, small studies have demonstrated the benefit of physical rehabilitation in the general well-being, functional capacity, autonomic heart control, respiratory muscle strength, and quality of life of CHD patients ${ }^{17-20}$. Larger studies on the implementation and cost-effectiveness of this muchvalued therapeutic approach are welcome and can contribute to the general goal of improving quality of life in patients with this highly neglected tropical disease.

\section{Conflict of interest}

The author declares that there is no conflict of interest.

\section{REFERENCES}

1. Benziger CP, do Carmo GAL, Ribeiro ALP. Chagas Cardiomyopathy: Clinical Presentation and Management in the Americas. Cardiol Clin. 2017;35(1):31-47.

2. França EB, Passos VMA, Malta DC, Duncan BB, Ribeiro ALP, Guimarães MDC, et al. Cause-specific mortality for 249 causes in Brazil and states during 1990-2015: a systematic analysis for the global burden of disease study 2015. Popul Health Metr. 2017;15(1):39.

3. Martins-Melo FR, Carneiro M, Ramos Jr AN, Heukelbach J, Ribeiro ALP, Werneck GL. The burden of Neglected Tropical Diseases in Brazil, 1990-2016: A subnational analysis from the Global Burden of Disease Study 2016. PLoS Negl Trop Dis. 2018;12(6):e0006559.

4. World Health Organization (WHO). Neglected Tropical Diseases. Genève: WHO; 2018. Accessed at August 5, 2018. Available at: http://www.who.int/neglected_diseases/en/.

5. Capuani L, Bierrenbach AL, Pereira Alencar A, Mendrone Jr A, Ferreira JE, Custer B, et al. Mortality among blood donos seropositive and seronegative for Chagas disease (1996-2000) in São Paulo, Brazil: A death certificate linkage study. PLoS Negl Trop Dis. 2017;11(5):e0005542.
6. Ribeiro AL, Nunes MP, Teixeira MM, Rocha MO. Diagnosis and management of Chagas disease and cardiomyopathy. Nat Rev Cardiol. 2012;9(10):576-89.

7. Costa HS, Lima MMO, da Costa FSM, Chaves AT, Nunes MCP, Figueiredo PHS, et al. Reduced functional capacity in patients with Chagas disease: a systematic review with meta-analysis. Rev Soc Bras Med Trop. 2018;51(4):421-26.

8. Rocha ALL, Rocha MOC, Teixeira BOS, Lombardi F, Abreu CDG, Bittencourt RJ, et al. Índice cronotrópico-metabólico na doença de Chagas. Rev Soc Bras Med Trop. 2005;38(5):373-6.

9. Rocha AL, Lombardi F, da Costa Rocha MO, Barros MVL, Val Barros VC, Reis AM, et al. Chronotropic incompetence and abnormal autonomic modulation in ambulatory Chagas disease patients. Ann Noninvasive Electrocardiol. 2006;11(1):3-11.

10. Raadschilders L, Rocha MOC, Sousa L, Nouwen J, Ribeiro AL. Is autonomic function associated with left ventricular systolic function in Chagas heart disease patients undergoing treatment for heart failure? Rev Soc Bras Med Trop. 2014;47(2):239-42.

11. Ribeiro AL, Moraes RS, Ribeiro JP, Ferlin EL, Torres RM, Oliveira E, et al. Parasympathetic dysautonomia precedes left ventricular systolic dysfunction in Chagas disease. Am Heart J. 2001;141(2):260-5.

12. Lins Barros MV, da Costa Rocha MO, Pinho Ribeiro AL, Santana Machado F. Tissue Doppler imaging in the evaluation of the regional diastolic function in Chagas' disease. Eur J Echocardiogr. 2001;2(2):94-9.

13. Lima MM, Nunes MC, Rocha MO, Beloti FR, Alencar MC, Ribeiro AL. Left ventricular diastolic function and exercise capacity in patients with Chagas cardiomyopathy. Echocardiography. 2010;27(5):519-24.

14. Chang WT, Liu YW, Liu PY, Hsu CH, Tsai WC. The association between right ventricular free wall strain and exercise capacity for health check-up subjects. PLoS One. 2017;12(3):e0173307.

15. Barros MV, Machado FS, Ribeiro AL, da Costa Rocha MO. Detection of early right ventricular dysfunction in Chagas' disease using Doppler tissue imaging. J Am Soc Echocardiogr. 2002;15 (10 Pt 2):1197-201.

16. Barbosa MPT, Carmo AAL, Rocha MOC, Ribeiro ALP. Ventricular arrhythmias in Chagas disease. Rev Soc Bras Med Trop. 2015;48(1):4-10.

17. Lima MMO, Rocha MOC, Nunes MCP, Sousa L, Costa HS, Alencar $\mathrm{MCN}$, et al. A randomized trial of the effects of exercise training in Chagas cardiomyopathy. Eur J Heart Fail. 2010;12(8):866-73.

18. Fialho PH, Tura BR, Sousa AS, Oliveira CR, Soares CCS, Oliveira $\mathrm{JR}$, et al. Effects of an exercise program on the functional capacity of patients with chronic Chagas' heart disease, evaluated by cardiopulmonary testing. Rev Soc Bras Med Trop. 2012;45(2):220-4.

19. Nascimento BR, Lima MMO, Nunes MCP, Alencar MCN, Costa HS, Pinto Filho MM, et al. Effects of exercise training on heart rate variability in Chagas heart disease. Arq Bras Cardiol. 2014;103(3):201-8.

20. Mediano MFF, Mendes FSNS, Pinto VLM, Silva PS, HasslocherMoreno AM, Sousa AS. Reassessment of quality of life domains in patients with compensated Chagas heart failure after participating in a cardiac rehabilitation program. Rev Soc Bras Med Trop. 2017;50(3):404-7. 